\title{
A Resilient Leadership for Resilient Cities
}

\author{
Cheick Fousseni Diaby ${ }^{1}$, Christophe Roux-Dufort ${ }^{1}$ \\ ${ }^{1}$ Laval University, Department of Management, 232, rue de la Terrasse Québec, Canada G1V OA6
}

\begin{abstract}
This theoretical paper takes an aesthetic view of leadership to investigate the leadership needed to make cities more resilient. It sees an urban system as a complex, evolving entity constantly crossed by a variety of inflows and outflows connecting it to other systems, while its constituent elements are in interaction between themselves. Three fundamental dispositions in the aesthetic literature - aesthetic sensibility, aesthetic reflexivity and practical wisdomseem crucial to ensure that leaders anticipate and cope with a variety of shocks, taking advantage of the available opportunities to transform the system and learn. These dispositions are found to be fundamental to urban resilience. The paper also discusses the implications for preparation and learning.
\end{abstract}

This paper investigates how an aesthetic view of leadership may be appropriate to deepen our understanding of urban resilience and bring more clarification about the conceptual tensions identified in the field. More particularly, we based our analysis on new avenues of research in the domain of leadership and particularly in aesthetic leadership, to expose three core dispositions developed by leaders in time of crisis that may be of precious help for leaders and managers in charge of building capacities to advance resilience: sensibility, reflexivity and wisdom. Doing so, we discuss the components of a proactive leadership oriented toward anticipation, and able to manage crises by discerning the opportunities lying behind chaos to construct the meaning necessary for learning. The paper starts with a brief presentation of the aesthetic perspective on leadership and follows up by the conceptual tensions identified in the review by Meerow, Newell and Stults (MNS) (Meerow et al., 2016) and the aesthetic response. A third part discusses the implications.

\section{What is aesthetic leadership?}

The aesthetic investigation focuses on the continuous interaction between individuals around various organizational artifacts (material ones like tools, or nonmaterial like ideas, plans, symbols, events) and how this influences the continuous construction, deconstruction and reconstruction of organizational life, eventually changing their environment (Strati, 1992, 2004, 2006). It particularly looks at the dynamics of the complex relationships between the organizational members interacting, the organization and its skills, the broader social and cultural context in which it is embedded and how all of these relate to each other (Woodward \& Funk,
2010); called the dynamics of the interaction. This aesthetic view attends to the practical and experiential ways in which leadership emerges from the continuous interaction between leaders and followers, their actions as they intersubjectively make sense of events and partly enact or transform their ongoing reality (Hansen et al., 2007; Koivunen \& Wennes, 2011; Ropo \& Sauer, 2008; Strati, 2003). Acknowledging that several realities may be valid despite their differences (Küpers, 2002), this view of leadership takes into account its blend of perceptive sensibility, judgment, persuasiveness, imagination and timing (Howard, 1996). There is a dimension of presenting oneself to others to perform with authenticity, and behaving in ways that respect others and their values by leaders striving for the beautiful or the common good (Ladkin \& Taylor, 2010; Ladkin, 2008). The literature on aesthetic leadership identifies three core dispositions of importance to the issue of resilience.

Aesthetic sensibility is related to engaging one's sensibilities and perceptive faculties to perceive and judge the significance of situations and events. It is also related to empathy, and understanding the aesthetic experience of others (Springborg, 2010; Strati, 2004; Weiskopf, 2002). Developed senses or faculties provide a precise, quick and thorough perception of objects. Such individuals' perception covers the ensemble of elements of the object of perception, with the ability to discern precisely the quality of each of its components with a clear feeling and confidence, even when variations occur. They understand how the parts report or relate to the main object and may judge accurately the quality of each component (Dewey, 1980; Hume, 1974). Taste is about promptly discovering with finesse the measure of pleasure things give us such as the pleasure from useful symmetry, balance or contrast (Montesquieu, 2012). Leaders with a developed aesthetic

\footnotetext{
${ }^{a}$ Corresponding author: author@e-mail.org

DOI 10.3311/FLOODRisk2020.13.12
} 
sensibility, often through practice and experience, are able to perceive a cue or event, even a small one, and sense its meaning and significance for the organization despite the uncertainty and complexity of the circumstances. They just know what it means. They empathetically relate to other stakeholders and are aware of how the latter feel and experience the event, their opinions and values. They spontaneously craft credible and original narrative performances that resonate with these audiences judging these performances convincing and authentic (Koivunen \& Wennes, 2011; Koivunen, 2007; Ladkin \& Taylor, 2010; Taylor \& Hansen, 2005).

Aesthetic reflexivity is related to the attitude of tuning in to the present moment both aware of what has happened before and anticipating what could happen next (Bathurst et al., 2010). It is an experiential way of knowing. The sensory-emotional elements of experience are used to create knowing and one may restructure interpretations to guide decision and action (Sutherland, 2013). One may know whether to act or not, as well as the proportion of an action to take in an interaction with the dynamic context that almost looks like a reflex (Ewenstein \& Whyte, 2007). To adapt to complex and uncertain contexts unceasingly evolving, leaders engage their sensibilities in successive reconstructions through hermeneutical rounds of sense making, decision and action (Woodward \& Funk, 2010). Aesthetic reflexivity opens up a space for the members of the group to exchange their tacit and aesthetic knowledge and construct a shared understanding of the unfolding situation. They listen and respond to each other, as they build the ongoing reality they are experiencing. They do so whilst being present in the now, constantly attending to the past and anticipating the future. The creativity of leadership lies in this aspect of considering more aspects of the situation at hand, as well as envisioning new possibilities. (Barrett, 2000; Ladkin \& Taylor, 2010; Palus \& Horth, 1996; Sutherland, 2013). This dialoguing in which they co-imagine (Küpers, 2002) their future and strive to create it is productively led by aesthetic leaders despite tension and paradox. These leaders are expected to remain focused and aware of how actions at the local level relate to the overall plan and rely on their senses to approve or disapprove of them, based on pleasantness/unpleasantness. They may notice small changes or cues, suspend their judgment to return to the past and reinterpret the event projected in the future; feeling what it means and intuitively knowing whether they carry on the same course of action or modify it, as well as to what extent. They may engage in more and more invention and improvisation. They may therefore rely on their sensibilities to spontaneously set priorities, maintain or change courses of action to various degrees, invent new and improvised solutions and set up new rules. Through their successive rounds of sensemaking, decision and action, they coordinate the ensemble of action to adapt and eventually regain control over the situation.

Practical wisdom, following Aristotle' phronesis, simply put means doing the right think at the right time in the right manner for the right reason (Aristote \& Crisp, 2014). It emerges from the contextual interactions of the individuals dialoguing and reflecting on their situation to evaluate and choose options (Küpers \& Statler, 2008). It is the dynamic disposition to sense, perceive, make choices and realize actions (Küpers \& Pauleen, 2015) as they spontaneously apprehend and experience situations in their broader context influencing how they think, feel and express themselves (Shotter \& Tsoukas, 2014). It translates in the ability to spontaneously imagine creative solutions that transcend and reconcile conflicting individual and collective interests, short term and longterm perspectives. Its embodiment is seen in leaders' way of interacting with people and artifacts to take decisive actions that make a difference and open up possibilities (Gärtner, 2011) of transformation. Similarly, the virtue component of practical wisdom may be seen in the ability to translate the moral and ethical norms of the broader social and cultural setting of embeddedness appropriately to the specific situation they experience. This ability to structure, unstructure and restructure in creative and improvised ways to adapt to changing and uncertain circumstances demands that they learn, unlearn and relearn.

These three dispositions seem to the authors at the heart of urban resilience, given the complexity of urban systems, the variety of shocks they are exposed to, the need for anticipation and adaptation, as well as the variety of stakeholders and the ethical issues at stake. The recent review by MNS acknowledges the lack of a common definition and identifies six conceptual tensions that an aesthetic leadership perspective may partly help resolve in our view. The paper builds on these findings to have a fresh look at urban systems and investigate the kind of leadership needed to build their resilience.

\section{Conceptual tensions in the urban resilience literature and the aesthetic take}

\subsection{Tension1\# City vs Urban system: complexity and adaptive capacity}

Beyond the various definitions available, MNS articulate urban resilience around four sub-components which are 'multi-scalar, networked, and often strongly coupled' (p.45). They stress 1) in the Governance Networks, the diversity of actors and institutions with differing interests shaping decisions 2) the variety of materials produced and consumed in cities in the Networked Material and Energy Flows 3) the built environment in the Urban Infrastructure and Form 4) and monetary capital, justice and equity, as well as the demographics implicated in the socio-economic demographics (among other things).

Instead of a static geographical entity, a city as an urban system, is complex and dynamic. It is composed of physical, social, ecological and technical networks in interaction, with emergent patterns of interaction between people, activities and processes, resources and institutions (Desouza \& Flanery, 2013; Godschalk, 2003; Pickett et al., 2013 ) in its context and its built environment. Moreover, the focal urban system also extends beyond the sole boundaries or administrative limits of the city (Ernstson et al., 2010). It is embedded in more global networks of resources, communication, and multilevel governance 
(Meerow et al., 2016). The focal urban system is also crossed inbound and outbound by a variety of flows (socioeconomic, human, ecological, technological, infrastructure, energy and so on) dynamically linking it to more or less distant other urban systems and places in a more or less loose connection. Land sciences adopt the concept of "telecoupling" to refer to these specific linkages and flows existing between distant regions and their effects on local social-ecological systems (Eakin et al., 2014). All of these interact with the broader social and cultural environment the focal urban system is embedded in, influencing the kind of institutions and governance mechanisms at play, the stakeholders involved and their power resources, as well as the legal and administrative rules it has to abide by.

The dynamics of how the individuals and groups pertaining to the focal urban system interact among themselves around the artifacts in emergent ways under their specific modes of governance, and how all these interact with their broader environment in relation to other places and spaces is seen hereafter as the dynamics of the interaction. The main thesis of this paper is that perceiving and understanding these dynamics when a disturbance occurs is fundamental to urban resilience, given the myriad of disturbances or shocks (varying in origin, type and intensity) that may affect the focal urban system in various ways and degrees at any point in time and space. The three dispositions mentioned may help improve our understanding. It is against the understanding of this dynamics that a cue or event is perceived and noticed (or not), projected in the future to imagine how it may affect the focal urban system (in which parts or components, the degree and speed) and judged important, urgent, risky and so on (or not). These decision makers must also be able to understand the perception of and convince various stakeholders in the social negotiation that will ensue. For MNS, the political aspect of urban resilience appears in this participatory and contested process. It will determine which meaning is eventually attributed to the event, which decision and action will be taken (or not). How quick and effective decision makers are at grasping the dynamics to feel what the event means will influence whether the city gets hit by a shock or not, as well as how effectively it responds to it. And this is a matter of aesthetic sensibility. The interplay of tacit and aesthetic knowledge makes the individual aware that he (She) knows what to do and drives him (her) to make decision and take action spontaneously and intuitively (Strati, 2003).

\subsection{Tension 2\# Adaptation to specific threats VS general adaptability}

Beyond this dualism, it appears that both the adaptation to specific threats and more general adaptability are critical (Wamsler et al., 2013). Not only is the urban system expected and often required under official regulations to take appropriate measures to prevent and prepare for known risks, but it is also expected to deal with unknown ones. It needs both to function under specific challenges and also to be able to face unpredictable threats (Walker \& Salt, 2012). One may therefore look at urban resilience as a way of thinking (Folke, 2006), making this adaptive capacity (Brown et al., 2012) of the urban system and all of its constituent networks across temporal and spatial scales critical to its resilience (Meerow et al., 2016). Recent news point to cases of known phenomena occurring at unexpected moments or places, or with an unusually high intensity, like alternations of extreme weather conditions. Some shocks may originate from more or less remote places and spaces and spread quickly to reach the focal urban system. These may take an economic, political or symbolic form among others, or even a combination thereof. These situations may raise multiform and interconnected challenges that no single procedure, agency or city can deal with by itself.

The capability needed is that of giving form, or that of doing something whilst one invents the mode of this doing (Pareyson, 1955). Merleau-Ponty sees form "wherever the properties of a system are modified by every change brought about in a single one of its parts and, on the contrary, are conserved when they all change while maintaining the same relationship among themselves" (Merleau-Ponty \& Waelhens, 2006). Namely, in the face of unexpected occurrences, these leaders need to stay focused, sense which processes and practices to shape in which forms; whilst maintaining the group and involving more and more persons to interact productively in order to adapt to continuously changing circumstances. The aesthetic dimension of orchestration in leadership is about bringing together a group of people with different abilities and successfully coordinating their energy to accomplish a goal (Duke, 1986). The authors see its practical elements in relation to aesthetic reflexivity, as what will influence if they adapt successfully or not to the unexpected.

Decision makers at the top of the urban system need to stay attune to the dynamics of the ongoing situation and engage in successive reconstructions of their interpretations each time the situation changes to understand what each new event means, which groups or parts of the system will be affected. They sense if and which processes and practices should be modified, as well as to what extent, in order to adjust. Taste, for Montesquieu, is what allows us to discern between when to abide by the rules of an art and when the exceptional situation should supersede the rules (Huisman \& Ribes, 1984). But also, they must keep the individuals, groups and agencies involved interacting critically to attend to each other's tacit and aesthetic knowledge productively, despite their conflicting views and interests. They establish a shared goal and continuously shape processes and practices, roles norms and forms of communication in various forms, distributing resources (material ones, authority and decision power). Their ability to remain open to other possibilities beyond the immediate and present ones is key to sense when and how to move vertically from the municipal to the regional to the state (or beyond) to mobilize and secure resources (funds, materials, expertise, people, political support), and horizontally with other places and spaces in order to get the necessary margin of maneuver.

Aesthetically reflexive leaders carry on this continuous shaping of forms through their rounds of sensemaking, decision and action to re-judge the situation each time it evolves until they regain control, based on how they feel. They include more and more people 
responsively to the situation and arrive at coordinating their actions (e.g. public agencies, private companies, volunteers, various social groups).

\subsection{Tension 3\# Mechanisms for system change between 1) persistence to resist disturbance 2) incremental adaptation 3 ) and radical transformation)}

Some researchers caution that it may not even be desirable to return to this original state (Holling \& Gunderson, 2002). This paper goes further to question whether this could even be possible in a foreseeable future in some cases (e.g. Tchernobyl, and Fukushima more recently). Nonetheless, deciding upon which state would be desirable or not involves an issue of judgment which may differ among people (Brown, 2014; Cote \& Nightingale, 2012).

Beyond the suggestion by MNS of a continuum from persistence to transformation, this issue may be approached in terms of an adequate proportion of change that varies contextually. The point therefore is how leaders make the decision related to the extent of change on this continuum. Leaders engaged in a course of action need to stay aesthetically reflexive in order to adjust to changes. Otherwise, there is a risk of over commitment to this ongoing course of action while the situation is evolving. Their effectiveness will be linked to their knowing if and when to act, what amount of action to take. Deciding whether to start slowly or rapidly, when to keep the same pace or to evolve is based on a judgment resorting to aesthetic categories, especially those related to rhythm.

Some examples of these categories concern keeping the same speed as what has gone before, gradually decreasing or increasing (by degrees), levels of velocity and agility (Boccagna, n.d.). The aesthetic reflexivity is what will allow leaders to feel the type of change to be made, the ability plan to produce the desired effects in time and space. When no solution in their repertoire suits the unusual situation, they may spontaneously invent new ones that they find plausible and capable of solving the problem at hand, on the fly; or decide to create new rules. Tacit knowledge is involved in adaptation to specific contexts and action-oriented (Epstein, 1998). These decisions often made intuitively are context-dependent, based on plausibility, not rational technical evidence. The feeling of comfort or discomfort, balance or unbalance, harmony or disharmony that they experience guides their spontaneous decision and action.

\subsection{Tension 4\# Timescale of action}

Urgency and rapid action remain important issues in resilience, be it before or when a shock occurs. Leaders are often blamed for not responding quickly enough (e.g. president Bush during Hurricane Katrina). Still, what is meant by rapid action is still not clear in the literature (Meerow et al., 2016). Besides, the temporal and spatial scale at which resilience is applied is influenced by contextual factors (Chelleri et al., 2015). The issue of time is a complex one that clock time fails to capture substantially. For Bergson, the property of time is to flow, it is not the spatialized description of a succession of points in space. On the contrary, real time as it is lived is experienced as a constant stream of emotions. It is related to constant change and invention (Bergson, 1934).

This paper considers it an issue of appropriate pace of change which is linked to rhythm. The fact that time is experienced subjectively comes with challenges for leaders. "Rapid" itself is a subjective judgment that may vary from one person to another. The accuracy of this judgment is related to one's attunement to the dynamics of the interaction, as well as the pace at which the shock or event unfolds, the actual and/or expected actions from a host of stakeholders. All of which occur under different temporal dynamics in the social setting and within implicated organizations. There are different times (e.g. holidays, night and day time) which organize activities in a given society (Hassard, 1990) and that may influence the resources available at a given moment, such as office hours. A problem occurring in daytime may raise different challenges than if it occurs during the night. Looking inside organizations, processes unfold at a different pace as well as within the various agencies and departments. To make it even more complex, the urgency is not felt in the same manner by the involved stakeholders. A victim trapped in a flooding and rescue team members may not feel the same level of urgency as others.

One may feel an urge or drag to do something (Epstein, 1998), but quality in this respect is related to sensibility and reflexivity. These translate in particular in the priorities of the moment set by leaders, and the succession of their actions in their plans. Thus, there are decisions about the direction to take to move forward, backward or to pause (and make preparations to take advantage of anticipated opportunities when they manifest). The subtlety is in setting the pace of change to judge with the categories slower and faster among others (or stopping). These categories themselves include several degrees or levels of intensity. For a sound and timely decision to be made, one needs to be constantly aware of the different temporal dynamics at play inside their organization as well as in their environment, to empathetically relate to various stakeholders to understand their motivations and goals. Ultimately, it is the consistency and the coherence of the series and actions that build up and converge toward the overall goal that gradually allows to regain control on the situation and imprint one's own rhythm on it.

\section{Discussion and concluding remarks}

Following these developments, the issue of leadership in urban resilience may be approached around these three core dispositions to open up interesting questions and partly respond to these " $5 \mathrm{~W}$ 's" of urban resilience which are actually interrelated in our view. Primarily, there is a need to understand and connect to the dynamics of the interaction. That is, how those with decision making power, often at the top of the urban system, relate to members of the various organizations and social groups, with the greater public composing the focal system. It is also about how all of these relate to and interact with the broader social and cultural context in which the focal system itself is embedded, i.e. the other urban systems, 
places and spaces it is related to under different jurisdictions, territorial divisions, landscapes and infrastructures and so on.

It may be that the core capacity to build is this adaptive capacity (Brown et al., 2012) which seems key to urban resilience. From an aesthetic perspective, this would entail the ability for leaders to sense the relationships between the different stakeholders, the physical infrastructures (water, building, transportation, energy, environmental) as well as intangible ones (e.g. communication, value systems) in their social and cultural context, and how they relate to other close or far areas, in order to understand the dynamics behind the way they are connected and constantly interacting. The accuracy of their perception at this level will influence how effectively they judge and evaluate threats, and consequently, the decisions they make. For, it is about making sense of a precise set of events in the specific situation to understand how it may unfold and impact on the urban system. From there on, one knows what to do to cope with it.

The trade-off related to the what (type of shocks, networks included, for generic or specific resilience?) varies with the contextual and situational demands. The point is how all of these interact, and how accurately and timely these are perceived and made sense of to take action. And this is a matter of aesthetic sensibility to grasp the dynamics at play.

Another trade-off, the when (rapid or slow-onset changes, short-term or long-term resilience, for present or future generations?) typically involves an aesthetically informed reflexivity and practical wisdom. As mentioned previously, rapid or slow, overt or covert changes are first and foremost a matter of sensibility and perception. Moreover, practically wise actions are manifest in these creative solutions that reconcile and transcend short and long-term interests. At its best, a resilient leadership should aim at solutions that solve the immediate problems faced and respond to the priorities of the moment, but not at the expense of future growth or sustainability. The answer here may lie, in complement to the timing, in the how and the why, as there is an effort to consider, reconcile and transcend the interests of multiple stakeholders, and timely enact the response guided by the pursuit of the greater good.

This in turn touches the why (the underlying motivations) and the Who (whose interest is given priority and who is included) trade-offs. Beautiful leadership is about striving for the greater good. What makes the action beautiful is also about how those in control interact respectfully with others and the values of the group (Ladkin, 2008). For Aristotle, the action is virtuous because the individual is animated by the right feeling for the right reason (Aristotle \& Crisp, 2014). One knowingly pursues the good with determination. The choices made at this level will determine whether resilience efforts end up in surface arrangements and a mere reproduction of social inequalities in new forms, or if there is a substantial change for the better and for the larger community. We expect this to especially manifest in the effort to include various voices in the dialoguing that may take place (e.g. in the resilience committees or crisis management teams set up to respond to shocks) and how effectively the interests of those at the margin of the urban system and society are taken into account in the deliberations make them part of the solution. Learning would then be seen in the policies following these episodes.

The implication is that preparing for and developing resilience may imply improving the readiness and ability of an urban system as a whole (with its different constituent bodies and people, social groups across different scales) 'to prepare... to be surprised and to improvise" with individuals or parties one is little or not at all used to working with (e.g. volunteers and general public, other cities and regions, private companies, unusual technologies or tools). That is, to join up their efforts and resources willingly in order to improvise effectively in the face of the unknown, at the required pace. This may make an urban system more open to considering a wider range of shocks as well as a larger set of practices and solutions from more and more diversified and unrelated industries or domains. Grasping the dynamics may potentially allow to better understand how the initiatives of the present may carry some of the future vulnerabilities as cities grow and expand (to absorb and incorporate industrial/chemical installations over time for example. In turn, these dispositions may contribute in effectively taking advantage of the learning opportunities that arise.

Finally, how these dispositions could be developed in the training of the personnel at multiple levels across the urban system seems an important issue for both research and practice for the authors. It may influence how the urban system is really able to cope with a variety of shocks, as well as which future vulnerabilities it is exposing itself to, knowingly or not.

\section{Conclusion}

The three interrelated dispositions presented in this paper -aesthetic sensibility, aesthetic reflexivity and practical wisdom- may represent core dispositions in achieving resilience in practice. These may improve the ability of an urban system to continuously reduce its exposure to risks and improving its ability to take advantage of opportunities. This view gives a more prominent role to affect, intuition and imagination than is currently acknowledged by the literature. It brings perception to the forefront of urban resilience and paves the way for practical ways of improving. Urban resilience is seen here as a dynamic process under construction. The paper identifies ways of solving some of the tensions persisting in the urban resilience literature. Being theoretical, the paper advances several arguments that would need to be further developed and tested.

\section{References}

1. Aristote, \& Crisp, R. (2014). Nicomachean ethics (a2414961; Revised edition). Cambridge University Press.http://www.loc.gov/catdir/enhancements/fy140 8/2014013623-t.html 
2. Barrett, F. J. (2000). Cultivating an aesthetic of unfolding: Jazz improvisation as a self-organizing system. The Aesthetics of Organization, 228-245.

3. Bathurst, R., Jackson, B., \& Statler, M. (2010). Leading aesthetically in uncertain times. Leadership, 6(3),311-330.

https://doi.org/10.1177/1742715010368761

4. Bergson, H. (1934). La pensée et le mouvant: Essais et conférences. Presses universitaires de France. http://ariane.ulaval.ca/cgi-bin/recherche.cgi?qu $=01$ 1151253

5. Boccagna, D. L. (n.d.). A Compendium of Agogic Terms. 354.

6. Brown, A., Dayal, A., \& Rumbaitis Del Rio, C. (2012). From practice to theory: Emerging lessons from Asia for building urban climate change resilience. Environment and Urbanization, 24(2), 531-556.

7. Brown, K. (2014). Global environmental change I: A social turn for resilience? Progress in Human Geography, 38(1), 107-117.

8. Chelleri, L., Waters, J. J., Olazabal, M., \& Minucci, G. (2015). Resilience trade-offs: Addressing multiple scales and temporal aspects of urban resilience. Environment and Urbanization, 27(1), 181-198.

9. Cote, M., \& Nightingale, A. J. (2012). Resilience thinking meets social theory: Situating social change in socio-ecological systems (SES) research. Progress in Human Geography, 36(4), 475-489.

10. Desouza, K. C., \& Flanery, T. H. (2013). Designing, planning, and managing resilient cities: A conceptual framework. Cities, 35, 89-99. Ariane Articles. https://doi.org/10.1016/j.cities.2013.06.003

11. Dewey, J. (1980). Art as experience (01-1099522). G. P. Putnam's Sons; Ariane. http://ariane.ulaval.ca/cgibin/recherche.cgi?qu $=01-1099522$

12. Duke, D. L. (1986). The aesthetics of leadership. Educational Administration Quarterly, 22(1), 7-27.

13. Eakin, H., DeFries, R., Kerr, S., Lambin, E. F., Liu, J., Marcotullio, P. J., Messerli, P., Reenberg, A., Rueda, X., \& Swaffield, S. R. (2014). Significance of telecoupling for exploration of land-use change. In Rethinking global land use in an urban era (pp. 141161). MIT Press.

14. Epstein, S. (1998). Constructive thinking: The key to emotional intelligence (01-0549140). Praeger; Ariane. http://ariane.ulaval.ca/cgibin/recherche.cgi?qu $=01-0549140$

15. Ernstson, H., Van der Leeuw, S. E., Redman, C. L., Meffert, D. J., Davis, G., Alfsen, C., \& Elmqvist, T. (2010). Urban transitions: On urban resilience and human-dominated ecosystems. Ambio, 39(8), 531545.

16. Ewenstein, B., \& Whyte, J. (2007). Beyond Words: Aesthetic Knowledge and Knowing in Organizations. Organization Studies, 28(5), 689-708. https://doi.org/10.1177/0170840607078080

17. Folke, C. (2006). Resilience: The emergence of a perspective for social-ecological systems analyses. Global Environmental Change, 16(3), 253-267.

18. Gärtner, C. (2011). Wisdom in the Flesh: Embodied Social Practices of Wisdom in Organisations.
Philosophy of Management, 10(1), 29-42. https://doi.org/10.5840/pom20111019

19. Godschalk, D. (2003). Urban Hazard Mitigation: Creating Resilient Cities. NATURAL HAZARDS REVIEW, 4(3), 136-143. Ariane Articles. https://doi.org/10.1061/(ASCE)15276988(2003)4:3(136)

20. Hansen, H., Ropo, A., \& Sauer, E. (2007). Aesthetic leadership. The Leadership Quarterly, 18(6), 544560. https://doi.org/10.1016/j.leaqua.2007.09.003

21. Hassard, J. (1990). The Sociology of time (011470565). St. Martin's Press; Ariane. http://ariane.ulaval.ca/cgi-bin/recherche.cgi?qu=011470565

22. Holling, C. S., \& Gunderson, L. H. (2002). Panarchy: Understanding transformations in human and natural systems. Island Press.

23. Howard, V. A. (1996). The Aesthetic Face of Leadership. Journal of Aesthetic Education, 30(4), 21. https://doi.org/10.2307/3333178

24. Huisman, B., \& Ribes, F. (1984). Les Philosophes et L'Art. Editions Bruno Huisman. Paris.

25. Hume, D. (1974). De la norme du goût. Les Essais Esthétiques, In Huisman, B., \& Ribes, F. (1984). Les Philosophes et L'Art. Editions Bruno Huisman. Paris.

26. Koivunen, N., \& Wennes, G. (2011). Show us the sound! Aesthetic leadership of symphony orchestra conductors. Leadership, 7(1), 51-71. https://doi.org/10.1177/1742715010386865

27. Koivunen, Niina. (2007). Collective expertise: Ways of organizing expert work in collective settings. Journal of Management and Organization, 15, 258276.

28. Küpers, W. (2002). Phenomenology of Aesthetic Organising-Ways Towards Aesthetically Responsive Organizations. Consumption, Markets and Culture, 5(1), 21-46.

29. Küpers, W. M., \& Pauleen, D. (2015). Learning wisdom: Embodied and artful approaches to management education. Scandinavian Journal of Management, 31(4), 493-500. https://doi.org/10.1016/j.scaman.2015.08.003

30. Küpers, W., \& Statler, M. (2008). Practically wise leadership: Toward an integral understanding. Culture and Organization, 14(4), 379-400.

31. Ladkin, D., \& Taylor, S. S. (2010). Leadership as art: Variations on a theme. Leadership, 6(3), 235-241. https://doi.org/10.1177/1742715010368765

32. Ladkin, Donna. (2008). Leading beautifully: How mastery, congruence and purpose create the aesthetic of embodied leadership practice. The Leadership Quarterly, 19(1), 31-41. https://doi.org/10.1016/j.leaqua.2007.12.003

33. Ladkin, Donna, \& Taylor, S. S. (2010). Enacting the 'true self': Towards a theory of embodied authentic leadership. The Leadership Quarterly, 21(1), 64-74.

34. Meerow, S., Newell, J. P., \& Stults, M. (2016). Defining urban resilience: A review. Landscape and Urban Planning, 147, 38-49. https://doi.org/10.1016/j.landurbplan.2015.11.011

35. Merleau-Ponty, M., \& Waelhens, A. de. (2006). La structure du comportement (i9782130554219; 3e éd. 
Quadrige). Quadrige/PUF; Ariane.

http://ariane.ulaval.ca/cgi-

bin/recherche.cgi?qu=i9782130554219

36. Montesquieu, C. de S. (1757). Essai sur le goût. In Huisman, B., \& Ribes, F. (1984). Les Philosophes et L'Art. Editions Bruno Huisman. Paris.

37. Palus, C. J., \& Horth, D. M. (1996). Leading Creatively: The Art of Making Sense. Journal of Aesthetic Education, 30(4), 53. https://doi.org/10.2307/3333180

38. Pareyson, L. (1955). Estetica. Teoria della formatività.

39. Pickett, S. T., Cadenasso, M. L., \& McGrath, B. (2013). Resilience in ecology and urban design: Linking theory and practice for sustainable cities (Vol. 3). Springer Science \& Business Media.

40. Ropo, A., \& Sauer, E. (2008). Dances of leadership: Bridging theory and practice through an aesthetic approach. Journal of Management and Organization, 14(5), 560.

41. Shotter, J., \& Tsoukas, H. (2014). In Search of Phronesis: Leadership and the Art of Judgment. Academy of Management Learning \& Education, 13(2), 224-243. https://doi.org/10.5465/amle.2013.0201

42. Springborg, C. (2010). Leadership as art-Leaders coming to their senses. Leadership, 6(3), 243-258. https://doi.org/10.1177/1742715010368766

43. Strati, A. (1992). Aesthetic Understanding of Organizational Life. The Academy of Management Review, 17(3), 568. https://doi.org/10.2307/258723

44. Strati, A. (2003). Knowing in practice: Aesthetic understanding and tacit knowledge. Knowing in Organizations: A Practice-Based Approach, 53-75.

45. Strati, A. (2004). Esthétique et organisation (i9782763781082). Les Presses de l’Université Laval; Ariane. http://ariane.ulaval.ca/cgibin/recherche.cgi?qu=i9782763781082

46. Strati, A. (2006). Organizational artifacts and the aesthetic approach. Artifacts and Organizations. Beyond Mere Symbolism, 23-39.

47. Sutherland, I. (2013). Arts-based methods in leadership development: Affording aesthetic workspaces, reflexivity and memories with momentum. Management Learning, 44(1), 25-43.

48. Taylor, S. S., \& Hansen, H. (2005). Finding form: Looking at the field of organizational aesthetics. Journal of Management Studies, 42(6), 1211-1231.

49. Walker, B., \& Salt, D. (2012). Resilience thinking: Sustaining ecosystems and people in a changing world. Island press.

50. Wamsler, C., Brink, E., \& Rivera, C. (2013). Planning for climate change in urban areas: From theory to practice. Journal of Cleaner Production, 50, 68-81.

51. Weiskopf, R. (2002). Deconstructing" The Iron Cage"-towards an Aesthetic of Folding. Consumption, Markets and Culture, 5(1), 79-96.

52. Woodward, J. B., \& Funk, C. (2010). Developing the artist-leader. Leadership, 6(3), 295-309. https://doi.org/10.1177/1742715010368768 